\title{
FIELD EVALUATIONS OF ATTRACTIVE TOXIC SUGAR BAIT STATION AND VEGETATION SPRAY APPLICATIONS FOR CONTROL OF AEDES AEGYPTI IN KEY LARGO, FLORIDA
}

\author{
DIANA P. NARANJO',2, LIN ZHU', KRISTOPHER L. ARHEART', DOUGLAS \\ FULLER ${ }^{3}$, GUNTER C. MULLER ${ }^{4}$, RUI-DE XUE ${ }^{5}$, WHITNEY A. QUALLS ${ }^{1,5}$ \\ 'Department of Public Health Sciences, University of Miami Miller School \\ of Medicine, Miami, FL 33136, USA
}

${ }^{2}$ Vysnova Partners Inc, Washington, DC 20036, USA

\begin{abstract}
${ }^{3}$ Department of Geography and Regional Studies, University of Miami, Coral Gables, FL 33124, USA
\end{abstract}
${ }^{4}$ Malaria Research and Training Center, Faculty of Medicine, Pharmacy and Odontostomatology, University of Sciences, Techniques and Technology of Bamako, Bamako, Mali, BP 1805, Bamako, Mali

${ }^{5}$ Anastasia Mosquito Control District, Saint Augustine, FL 32080, USA

\author{
Guest Editor: Amy Junnila
}

\begin{abstract}
Aedes aegypti and Aedes albopictus, vectors of many arboviruses including Zika, dengue, and chikungunya, are difficult to control with traditional methods. We tested two novel approaches utilizing attractive toxic sugar baits (ATSB) against $A e$. aegypti in the upper Florida Keys. Residential sites on the island of Key Largo were systematically selected using Google maps. Sites received either bait stations or vegetation spray application with ATSB. An untreated control site was selected to monitor mosquito populations. Adult and egg counts were monitored through baited BiogentsSentinel and oviposition traps. The treatment evaluation lasted 28 days following a 14-day pre-treatment evaluation. Treatment efficacy was evaluated using regression models to estimate the percent reduction of mosquitoes over time. Post-treatment, Ae. aegypti mosquito populations were reduced by $81 \%$ and $74 \%$ at days 7 and $28(\mathrm{p}<0.05)$ at the bait station site, while mosquito populations at the spray treatment site for the same period ( 7 to 28 days) were reduced by $66 \%$ and $82 \%(\mathrm{p}<0.05)$, respectively. Treatment and time had no significant effect on the proportion of eggs collected after the application of the ATSB treatments. This is the first residential field trial against the Zika vector, Ae. aegypti, in South Florida that demonstrated successful reduction of female and males using both ATSB stations and vegetation spray treatments. The findings suggest that 1) ATSB stations and vegetation spray applications can reduce populations of Ae. aegypti in residential and semi-tropical areas at least up to 28 days and 2) Ae. aegypti female mosquitoes in South Florida feed on sugar, and their sugar-feeding behavior can be exploited to enhance control strategies.
\end{abstract}

Key Words: sugar-feeding, integrated vector management, urban vectors, Aedes aegypti

\section{INTRODUCTION}

Aedes aegypti (Linnaeus) (Skuse) serves as primary vector of Zika (ZIKV), dengue, and chikungunya (Ioos et al. 2014). Vector control has been the only resource available to protect the human population against $A e$. aegypti vectored arboviruses. However, vector control of this species has been difficult
(Barreto et al. 2011, Gubler 2011, Naranjo et al. 2014) due partly to its survival mechanism and high adaptability to the environment. Aedes aegypti eggs survive from 2 to 12 months (Faull and Williams 2015), even at temperatures of $10^{\circ} \mathrm{C}$ (Waldock et al. 2013). Larval development occurs in many different habitats, from man-made to natural, through a skip oviposition pattern for dispersal (Reiter 
2007). For instance, both water bottle caps and tree holes, are suitable for Aedes aegypti development in residential areas if filled with water from 3 to 5 days (Reiter 2007). In addition, focal control with insecticides is costly, may result in community opposition, and a loss of control due to insecticide resistance. Source reduction is rarely effective as it relies on high levels of community participation (Reiter 2007, Troyo et al. 2008, Unlu et al. 2013). Therefore, when the environment favors Aedes-vector populations with suitable climate, home-to-home control becomes futile (Reiter 2007, Troyo et al. 2008).

Attractive toxic sugar bait (ATSB) is a novel method to deliver insecticides to mosquitoes. Even though blood-feeding studies argue that sugar-feeding is unimportant for female Ae. aegypti (Scott et al. 2000, Edman et al. 1992, Harrington et al. 2001), there is growing evidence that sugar enhances the survivorship and fitness of female Ae. aegypti mosquitoes (Gary and Foster 2006, Qualls et al. 2016). ATSB can enhance integrated vector management approaches by targeting the sugar-feeding behavior of mosquitoes. Laboratory and field trials have demonstrated that Aedes albopictus Skuse can be lured to an attractive toxic sugar bait infused with oral toxins such as boric acid (Naranjo et al. 2013, Junnila et al. 2015).

ATSB can be adapted to different settings both indoors and outdoors (Revay et al. 2014, Qualls et al. 2015), which is important due to the behavioral adaptability and peridomestic preferences of Ae. aegypti and Ae. albopictus (Bonizzoni et al. 2013, Rodrigues et al. 2015). In field trials, ATSB as bait stations and spray treatments decimated Aedes, Culex, and Anopheles species from arid areas in Mali (Qualls et al. 2015), and sub-tropical environments in Florida (Revay et al. 2014, Qualls et al. 2014). Individual-based models demonstrated the effectiveness of ATSB stations in controlling An. gambiae Giles mosquitoes and malaria parasite transmission in typical African village settings (Zhu et al. 2015). Three field experiments of vegetation spray application of ATSB, with boric acid and eugenol, significantly reduced $A e$. albopictus and other vector-populations in residential areas of St. Augustine, FL (Naranjo et al. 2013, Revay et al. 2014, Qualls et al. 2014). The reduction in Ae. albopictus with ATSB control persisted under warm and rainy conditions for at least 21 days in comparison to control sites (Naranjo et al. 2013).

Implementation of ATSB methods in key regions of the U.S. that serve as ports of entry and export for Aedes may reduce arbovirus risk. Sub-tropical and tropical Southern U.S. counties sustain Aedes populations year round (Monaghan et al. 2016). Moreover, these areas also serve as destinations for travelers worldwide. The confluence of infected travelers from Zika-endemic regions, suitable climate, and the presence of infected mosquito-vectors, resulted in local transmission in both Miami and Texas. At of the end of 2016, there were 216 locally acquired Zika cases in Florida and 6 in Texas (Centers for Disease Control and Prevention 2016 a, b). These recent outbreaks raise concerns about how to sustainably control Zika vectors in the tropical environments of the U.S. Hence, our motivation to test approaches utilizing ATSB to control Ae. aegypti in residential areas of South Florida.

\section{MATERIALS AND METHODS}

This study was conducted in residential areas of the island of Key Largo, FL located in the upper Florida Keys (25.086515 N latitude, $-80.447281 \mathrm{~W}$ longitude). The total surface area of the city is $53 \mathrm{~km}^{2}$. Key Largo temperatures range from 24 to $32^{\circ} \mathrm{C}$ from May through November; rains and high humidity are a common daily occurrence during the wet season from May-November. From December through April, temperatures fluctuate between 18 and $29^{\circ} \mathrm{C}$, and the atmospheric humidity decreases. Adult mosquitoes tend to be more active from May through September.

The study sites were systematically selected on the island of Key Largo, FL using Google maps. Eligible study sites were selected using criteria based on the built environment. Eligibility was met if the residential block of houses was surrounded by 3 or 4 streets, and by other residential blocks. 
Streets and roads have shown to provide an ecological barrier against contamination across sites, meaning that the vector presence is significantly contained within city blocks (Barbu et al. 2013, Coffin 2007). The same barrier applies to Ae. aegypti, as Hemme and colleagues detailed in the study of the effect of highways and dispersal patterns of this species (Hemme et al. 2010).

The selection criteria for study sites reduced the chance that mosquitoes would disperse between blocks. The distance between any two study sites was $>500 \mathrm{~m}$. Nine eligible study sites were initially identified and after the first field visit, we further narrowed it to seven sites. Of these, one site was excluded per resident request. The final sample size was six study sites. One site was used as the control, two sites received bait station treatment, and three sites received spray treatment around the perimeter vegetation. The perimeter and area of all study sites was measured, and a 14day pretreatment population abundance evaluation was conducted. This study was conducted from mid-July through September of 2016.

All non-flowering vegetation in the perimeter of the three sites selected for the vegetation spray were treated with $\mathrm{C} / \mathrm{S} \mathrm{Pi}$ lot ATSB Mosquito Bait Concentrate (Westham Co.; Dallas, TX; active ingredients $0.4 \%$ sesame oil and $0.2 \%$ cinnamon oil) using a 4-gallon pump-up sprayer (Westward Parts Services Ltd.). Per label instructions, a 32-ounce pouch was mixed with 64 ounces of water and applied as a barrier treatment to the non-flowering vegetation (Terminix All Clear ${ }^{\circledR}$ C/S Pilot Mosquito Bait Concentrate; Dallas, Texas, Westham Co. 2016). Given that the mean flight height of Aedes species is approximately 1 $\mathrm{m}$, vegetation was sprayed no higher than $1 \mathrm{~m}$ above the ground (Bidlingmayer et al. 1981, Bellini et al. 1997). Both the top and bottom surfaces of the leaves were sprayed to protect the active ingredient from rain events.

Bait stations used for this study were $2^{\text {nd }}$ generation prototypes developed by West-

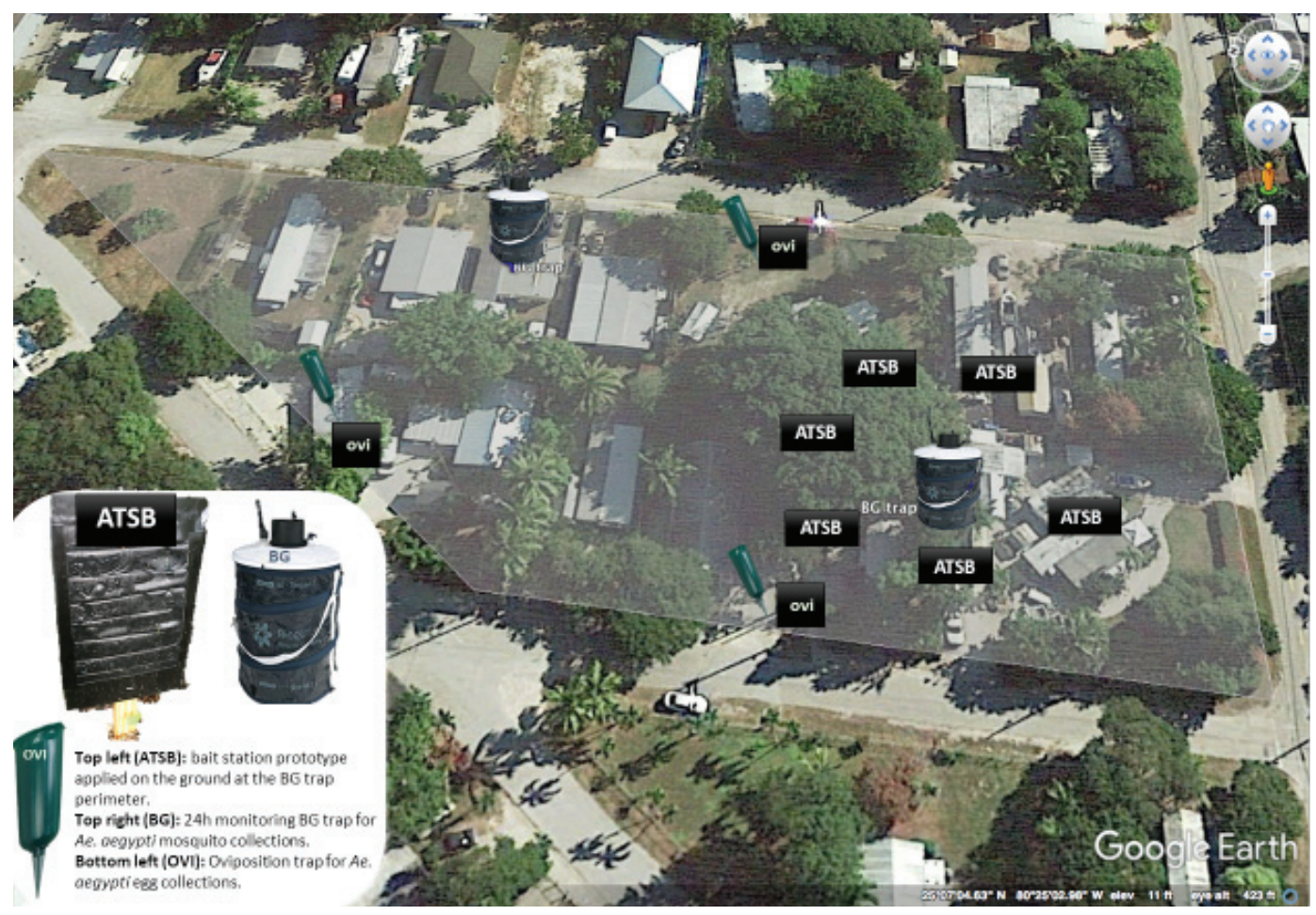

Figure 1. Google earth images displaying a sample configuration of the bait station treatment with attractive toxic sugar baits (ATSB) in Key Largo, FL. 
ham Co. that measured $28 \mathrm{~cm} \times 22 \mathrm{~cm}$. The ATSB Bait Station (Westham Ltd.; Tel Aviv, Israel) was fabricated from a white, layered, laminated sheet (polyethylene and polyethylene terephthalate). The bait stations were fused to a membrane made of styreneethylene butylene styrene and specially designed so that mosquitoes could sugar-feed. Several crossing seams created 16 cells which were filled with $4 \mathrm{ml}$ of the ATSB containing $0.04 \%$ sesame oil and $0.2 \%$ cinnamon oil as the active ingredients, microencapsulated with 1.5 beta-cyclodextrin, all parts in weight volume percent. A thick polyethylene pane provided support for the bait stations, which were attached to wood stake and inserted in the ground to be about 25 centimeters off the ground. Six bait stations were placed every $10 \mathrm{~m}$ around one of the Biogent (BG) Sentinel traps (Biogents AG, Regensburg, Germany) following a recommended configuration in consideration of both flight range of Aedes mosquitoes and past ATSB configuration studies (Muller et al. 2011, Qualls et al. 2016, Zhu et al. 2015) (Figure 1).

For all the evaluations, mosquito populations were monitored using entomological methods. These included the use of $\mathrm{CO}_{2}$ and lure-baited BG Sentinel traps and nonbaited oviposition traps (ovi-traps). Two BG Sentinel traps were set in backyards and in vegetative areas at each site for $24 \mathrm{~h}$ every 7 days. The battery-operated traps were set between 7 am and 9 am on Mondays and collected after a 24-hour period. The nets were retrieved from the traps and trapped mosquitoes were transferred to a cooler for transportation. Mosquitoes were then moved to the lab freezer for later identification to species and gender.

Ovi-traps were placed out in the field and left at the same locations for the duration of the project. There were three ovi-traps at each study site, which were placed separate from each other and from the BG-Sentinel traps by at least $40 \mathrm{~m}$. The ovi-traps were emptied and then filled with distilled water at each visit every 7 days. Oviposition papers were placed at the first visit and removed, and replaced at each subsequent visit. The removed oviposition papers were placed in individual plastic bags and transferred to the laboratory for later inspection and egg counting under the microscope.

Excluding planning, the field trial timeline included a 7-day site location selection period, 14 days of pre-treatment evaluation, and 28 days post-treatment monitoring. At post-treatment days 10 to 14 , cumulative rainfall reached $5 \mathrm{~cm}$. Additionally, at 10days post-treatment, $20 \mathrm{~m}$ of treated vegetation at one study site were removed by landscape workers.

Consent was obtained from the Florida Keys Mosquito Control District for this entomological evaluation. To inform the community, we prepared flyers with the description of the trial prior to treatment applications and included our contact information at the University of Miami.

Collections of Ae. aegypti and other mosquito species by trap (gender and species) and eggs were recorded. A generalized linear model (GLM) and a negative binomial distribution was used for the analysis. The GLM helped estimate the means at each treatment site and day. Means served as the baseline to calculate percent changes in the number of eggs and adult Ae. aegypti over the three-week treatment evaluation period. The means were compared by time and treatment application to the control site. The main analysis was conducted with female Ae. aegypti counts, however, we conducted secondary analyses with male and females together, and males alone to check for the consistency of results. To assess random error in the estimates, an alpha of 0.05 and $95 \%$ confidence interval was used for the analyses. The data was analyzed using descriptive analysis, and proc glimmix for the GLM model and planned comparisons using the percent change as our outcome. Software use was SAS Statistical Software v9.3 (SAS Institute Inc. Cary, NC).

\section{RESULTS AND DISCUSSION}

During the study, there were 924 female and 289 male Ae. aegypti collected, in the BG Sentinel traps. The total catches of Ae. albopictus were 19 females with no males collected 
during the study period. In addition, 1,053 female Aedes taeniorhynchus (Wiedemann) were collected. There were 1,155 Aedes eggs collected in 21 ovitraps throughout the evaluation.

Overall, the control populations of female Ae. aegypti were relatively stable yielding pre-treatment means of $34 \pm 13.3 \mathrm{SE}$ and post-treatment means of $21.25 \pm 8.6 \mathrm{SE}$. There were no significant differences in the control collections before and after the ATSBs evaluation $(p>0.05)$. After the ATSB bait station and vegetation spray applications populations declined significantly compared to pre-treatment populations (Figure 2). The pre-treatment mean of $19.5 \pm 5.9 \mathrm{SE}$ Ae. aegypti females per trap decreased to 2 $\pm 0.9 \mathrm{SE}$ at the bait station application site with an overall $90 \%$ reduction. At the vegetation spray application site, the pre-treatment mean decreased from $26.9 \pm 6.9 \mathrm{SE}$ to $7.3 \pm$ $1.9 \mathrm{SE}$ resulting in a $72 \%$ reduction in Ae. $a e-$ gypti female populations. When comparing pre-treatment collections at the bait station application site to post-treatment collections at days 7, 14, 21, and 28 (days 21, 28, 35, 42 in Fig. 2), the percent reduction in $A e$ e aegypti populations was $81 \%, 96 \%, 89 \%$, and $74 \%$, respectively. All these changes were statistically significant $(p<0.001)$. When comparing the vegetation spray application site pre-treatment collections to post-treatment collections, the percent reductions at day 7, 14, 21, and 28 (days 21, 28, 35, 42 in Fig. 2) were $66 \%(\mathrm{p}=0.003), 44 \%(\mathrm{p}=0.09), 91 \%$ $(<0.001)$, and $82 \%(<0.001)$, respectively.

Area, perimeter, or site characteristics did not confound the relationship of treatment and time on the total mosquito population and therefore were excluded from the analysis. The results from the male counts tested alone, and the female and male counts tested together were consisted with female $A e$. aegypti results. Our analysis accounted for missing data. We missed 5.3\% (3/56) observations of adult catches and $5.6 \%(7 / 126)$ of oviposition papers.

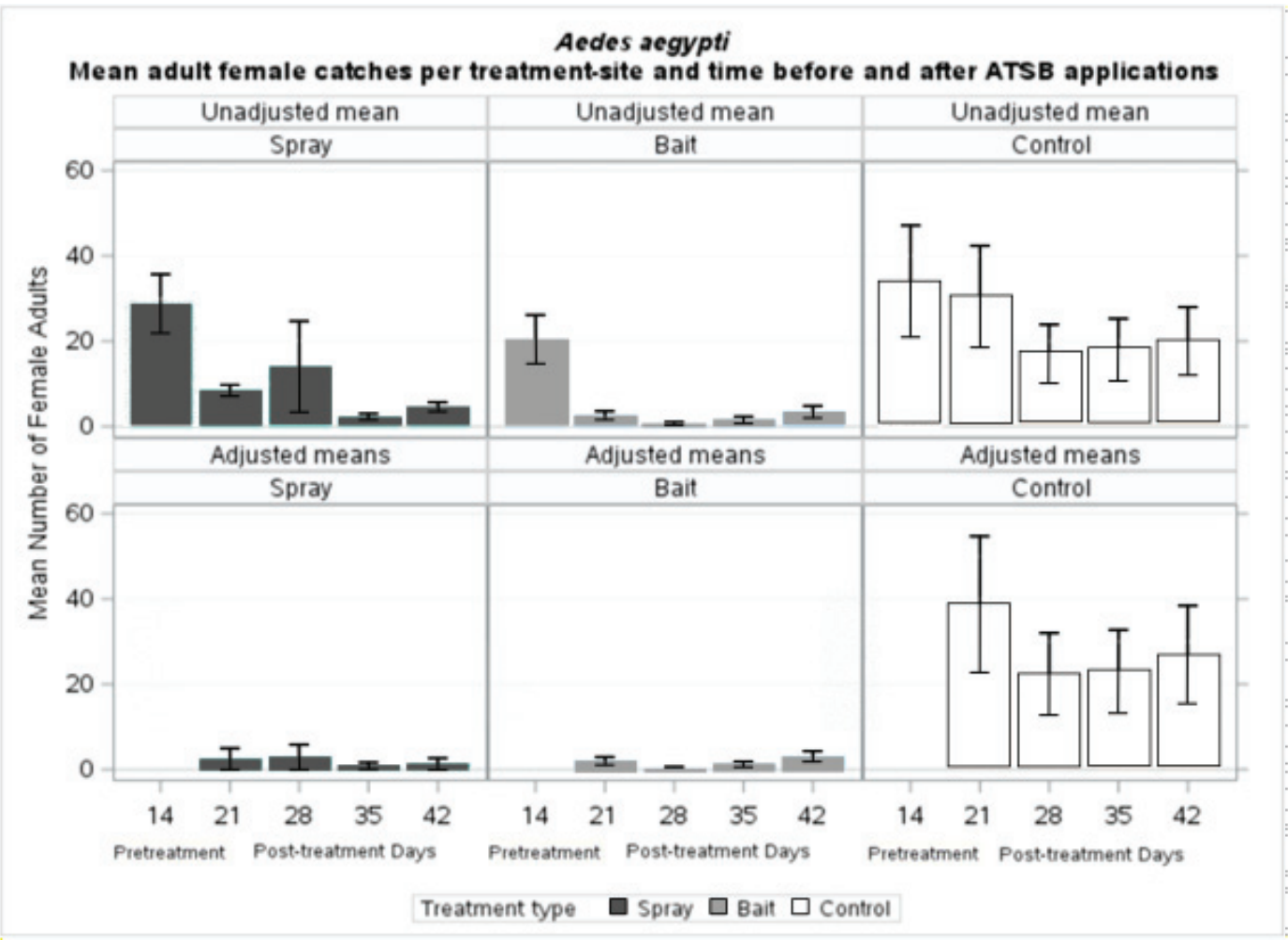

Figure 2. Unadjusted and adjusted means for pre-treatment of female Aedes aegypti mosquitoes at the vegetation spray and bait station applications, and the Control site at pre-treatment day 14 and post-treatment days 21-42 
Overall, there were significantly fewer Ae. aegypti mosquitoes after the application of both ATSB bait station and vegetation spray methods in comparison to pretreatment numbers. The female mosquito data, and the combined male and female data demonstrated a significant decrease in mosquitoes at the treatment sites. Significant population reductions by both treatments persisted throughout the study, up to 28 days post-treatment. It is consistent with results from previous field trials which demonstrate that ATSB applications resulted in reductions that lasted for 21 days in tropical settings (Naranjo et al. 2013, Xue et al. 2011). Previous caged experiments in tropical environments comparably showed that boric acid sugar baits applied to plant foliage resulted in estimates of 80 to $100 \%$ mortality in Ae. albopictus populations within $48 \mathrm{~h}$ (Xue et al. 2006). Additionally, in drier environments in Israel, Ae. aegypti populations collapsed 4-days post ATSB treatment and dropped steadily for 27 days (Junnila et al. 2015) .

During the post-treatment time, the sprayed vegetation was partially removed at one site by landscapers for a new home construction. Removal of the treated vegetation could explain why the population reduction was not significant at day 14 posttreatment at the vegetation spray treatment sites. Yet, even after intense rain events, the spray treatment on vegetation resulted in significant overall control of adult Ae. aegypti populations. Despite field challenges, such as executing optimum ATSB bait station configuration, the bait station treatment successfully controlled Ae. aegypti popula- tions in two residential sites. Only six bait stations were needed to show a reduction in the number of mosquitoes as measured by BG-Sentinel traps at the application sites compared to the pre-treatment controls.

The effect of treatment did not have a significant impact $(p=0.103)$ on the egg population. The interaction between treatment and control site was also not significant $(p=0.660)$ (Table 1). Although, the proportion of eggs, measured through ovi-traps, decreased only immediately after treatment at day 28 (day 7 post-treatment; $p<0.05$ ). Our findings are similar to other trials where multiple comparisons of different trapping methods in China showed Aedes adult monitoring with BG-Sentinel traps was more representative of measuring Aedes populations than ovi-traps ( $\mathrm{Li}$ et al. 2016).

Our study suggests that female Ae. aegypti mosquitoes will feed on sugar in the field, which is contrary to the common belief that they feed only on blood if given the option (Scott et al. 2000). In Thailand, mark and recapture trials showed that released and wild females fed unfrequently on natural sugar sources (Edman et al. 1992). Such results are challenged by the speed in which sugar is processed in the mosquito gut and by not having the same collection method for males to perform fair comparisons (Edman et al. 1992). Diptera, Culicidae. Qualls et al. (2016) demonstrated that in urban environments in Ecuador, more Ae. aegypti females than males sugar fed on marked natural sugar sources from a distance of up to $60 \mathrm{~m}$ away from the marked sugar sources. Results of our study provide further evidence that female Ae. aegypti feed on sugar in the field,

Table 1. Egg collections means and standard errors (SE) per treatment time at the Control and ATSB bait station and ATSB vegetation spray treatment sites.

\begin{tabular}{lcccc}
\hline \hline & Day & Control (SE) & Bait Station (SE) & Vegetation Spray (SE) \\
\hline Pre-treatment & 7 & $2.7(2.4)$ & $4.6(3.1)$ & $4.0(2.3)$ \\
& 14 & $2.3(2.1)$ & $3.5(2.6)$ & $4.2(2.1)$ \\
Post-treatment & 21 & $24.3(19.9)$ & $1.67(1.1)$ & $7.9(4.0)$ \\
& 28 & $22.7(18.6)$ & $4.2(2.8)$ & $7.0(3.6)$ \\
& 35 & $39.0(31.8)$ & $16.5(9.6)$ & $15.4(7.3)$ \\
\hline
\end{tabular}

*There were 7 missing observations of egg counts in oviposition traps from a total of 126 collections. 
that sugar-feeding behavior can be targeted in integrated vector management programs of Aedes. ATSB presented in the field as either a bait station or a vegetation spray treatment can be used to reduce the numbers of these mosquitoes.

Regarding limitations, this study was not a randomized control trial, therefore it may be prone to selection bias. To minimize bias, the sites were systematically selected based on the rule that a block of houses had to be surrounded by three to four streets. This sampling approach reduced the number of eligible sites. The active ingredients and application method of ATSB have been further modified to withstand rain events and can contain a variety of environmentally friendly active ingredients as oral toxins (Muller and Schlein 2011). However, additional testing is needed to achieve optimal configurations and prototypes in tropical settings. The bait station membrane lost integrity in the environmental conditions during the field study and further research is needed to optimize the bait membrane.

This is the first field residential trial of ATSB against the important Zika vector, Ae. aegypti in South Florida that demonstrates successful population reductions using both ATSB bait stations and vegetation spray treatments. The island of Key Largo provides highly suitable conditions for survival of $A e$. aegypti and our field trial suggests that if ATSB is employed routinely, it will limit the survival of this species. ATSB continued to reduce Ae. aegypti populations under rainy and tropical conditions. Reduction in the population of vector mosquitoes in residential areas also reduces vectorhuman contact. This is an important consideration regarding Zika transmission in residential areas in South Florida and other tropical regions.

\section{ACKNOWLEDGEMENTS}

We would like to acknowledge the community of Key Largo, FL and the Florida Keys Mosquito Control District for their support in conducting this research study. This research was conducted under a grant
66664-3616 mosquito research funding number 2016-03, from Westham Co. (Dallas, Texas) to the University of Miami Miller School of Medicine, Department of Public Health Sciences.

\section{REFERENCES CITED}

Barbu CM, Hong A, Manne JM, Small DS, Calderón JEQ, Sethuraman K, Quispe-Machaca V, AnccaJuárez J, del Carpio JGC, Chavez FSM, Náquira C, Levy M. 2013. The effects of City streets on an Urban desease vector. PLoS Comput Biol 9: e1002801. doi: 10.1371/journal.pcbi.1002801

Barreto ML, Teixeira MG, Bastos FI, Ximenes RA, Barata RB, Rodrigues LC. 2011. Successes and failures in the control of infectious diseases in Brazil: social and environmental context, policies, interventions, and research needs. Lancet 377: 1877-1889.

Bellini R, Veronesi R, Draghetti S, Carrieri M. 1997. Study on the flying height of Aedes caspius and Culex pipiens females in the Po Delta area, Italy. J Am Mosq Control Assoc 13: 356-360.

Bidlingmayer WL, Hem DG. 1981. Mosquito flight paths in relation to the environment effect of the forest edge upon trap catches in the field. Mosq News 41: 55-59.

Bonizzoni M, Gasperi G, Chen X, James AA. 2013. The invasive mosquito species Aedes albopictus: current knowledge and future perspectives. Trends Parasitol 29: 460-468.

Centers for Disease Control and Prevention. 2016a. Case counts in the US.

CDC Issues Zika Virus Guidance for Brownsville, Texas. 2016b. Retrieved from https://www.cdc.gov/ media/releases/2016/s1214-brownsville-texas-zikaguidance.html.

Coffin AW. 2007. From roadkill to road ecology: a review of the ecological effects of roads. J Transport Geo 15: 396-406.

Edman JD, Strickman D, Kittayapong P, Scott TW. 1992. Female Aedes aegypti (Diptera, Culicidae) in Thailand rarely feed on sugar. J Med Entomol 29: 10331038.

Faull KJ, Williams CR. 2015. Intraspecific variation in desiccation survival time of Aedes aegypti (L.) mosquito eggs of Australian origin. J Vect Ecol 40: 292-300.

Gary RE Jr, Foster WA. 2006. Diel timing and frequency of sugar feeding in the mosquito Anopheles gambiae, depending on sex, gonotrophic state and resource availability. Med Vet Entomol 20: 308-316.

Harrington LC, Edman JD, Scott TW. 2001. Why do female Aedes aegypti (Diptera: Culicidae) feed preferentially and frequently on human blood? $\mathrm{J} \mathrm{Med}$ Entomol 38: 411-422.

Hemme RR, Thomas CL, Chadee DD, Severson DW. 2010. Influence of urban landscapes on population dynamics in a short-distance migrant mosquito: evidence for the dengue vector Aedes aegypti. PLoS Negl Trop Dis 4: e634.

Ioos S, Mallet HP, Leparc GI, Gauthier V, Cardoso T, Herida M. 2014. Current Zika virus epidemiology and recent epidemics. Med Mal Infect 44: 302-307.

Junnila A, Revay EE, Muller GC, Kravchenko V, Qualls WA, Xue RD, Allan SA, Beier JC, Schlein Y. 2015. Efficacy of 
attractive toxic sugar baits (ATSB) against Aedes albopictus with garlic oil encapsulated in beta-cyclodextrin as the active ingredient. Acta Trop 152: 195-200.

Li Y, Su X, Zhou G, Zhang H, Puthiyakunnon S, Shuai S, Cai S, Gu J, Zhou X, Yan G, Chen XG. 2016. Comparative evaluation of the efficiency of the BG-Sentinel trap, CDC light trap and Mosquito-oviposition trap for the surveillance of vector mosquitoes. Parasit Vectors 9: 446.

Monaghan AJ, Morin CW, Steinhoff DF, Wilhelmi O, Hayden M, Quattrochi DA, Reiskind M, Lloyd AL, Smith K, Schmidt CA, Scalf PE, Ernst K. 2016. On the seasonal occurrence and abundance of the Zika Virus vector mosquito Aedes aegypti in the contiguous United States. PLoS Curr 8.

Müller GC, Schlein Y. 2011. Different methods of using attractive sugar baits (ATSB) for the control of Phlebotomus papatasi. J Vect Ecol 36: S64-S70.

Naranjo DP, Qualls WA, Muller GC, Samson DM, Roque D, Alimi T, Arheart K, Beier JC, Xue RD. 2013. Evaluation of boric acid sugar baits against Aedes albopictus (Diptera: Culicidae) in tropical environments. Parasitol Res 112: 1583-1857.

Naranjo DP, Qualls WA, Jurado H, Perez JC, Xue RD, Gomez E, Beier JC. 2014. Vector control programs in Saint Johns County, Florida and Guayas, Ecuador: successes and barriers to integrated vector management. BMC Public Health 14: 674.

Population estimates. Retrieved from http://www.census.gov/quickfacts/table/PST045215/1236375, 1236300, 00 .

Qualls WA, Muller GC, Revay EE, Allan SA, Arheart KL, Beier JC, Smith ML, Scott JM, Kravchenko VD, Hausmann A, Yefremova ZA, Xue RD. 2014. Evaluation of attractive toxic sugar bait (ATSB)-Barrier for control of vector and nuisance mosquitoes and its effect on non-target organisms in sub-tropical environments in Florida. Acta Trop 131: 104-110.

Qualls WA, Muller GC, Traore SF, Traore MM, Arheart KL, Doumbia S, Schlein Y, Kravchenko VD, Xue RD, Beier JC. 2015. Indoor use of attractive toxic sugar bait (ATSB) to effectively control malaria vectors in Mali, West Africa. Malaria J 14: 301.

Qualls WA, Naranjo DP, Subia MA, Ramon G, Cevallos V, Grijalva I, Gomez E, Arheart KL, Fuller DO, Beier JC. 2016. Movement of Aedes aegypti following a sugar meal and its implication in the development of control strategies in Duran, Ecuador. J Vect Ecol 41: 224-231.
Reiter P. 2007. Oviposition, dispersal, and survival in Aedes aegypti: implications for the efficacy of control strategies. Vector-Borne and Zoonotic Dis 7: 261-273.

Revay EE, Muller GC, Qualls WA, Kline DL, Naranjo DP, Arheart KL, Kravchenko VD, Yefremova Z, Hausmann A, Beier JC, Schlein Y, Xue RD. 2014. Control of Aedes albopictus with attractive toxic sugar baits (ATSB) and potential impact on non-target organisms in St. Augustine, Florida. Parasitol Res 113: 7379.

Rodrigues MM, Marques GR, Serpa LL, Arduino B, Voltolini JC, Barbosa GL, Andrade VR, de Lima VL. 2015. Density of Aedes aegypti and Aedes albopictus and its association with number of residents and meteorological variables in the home environment of dengue endemic area, Sao Paulo, Brazil. Parasit Vectors 8: 115 .

Scott TW, Amerasinghe PH, Morrison AC, Lorenz LH, Clark GC, Strickman D, Kittayapong P, Edman JD. 2000. Longitudinal studies of Aedes aegypti (Diptera: Culicidae) in Thailand and Puerto Rico: blood feeding frequency. J Med Entomol 37: 89-101.

Troyo A, Calderon-Arguedas O, Fuller DO, Solano ME, Avendano A, Arheart KL, Chadee DD, Beier JC. 2008. Seasonal profiles of Aedes aegypti (Diptera: Culicidae) larval habitats in an urban area of Costa Rica with a history of mosquito control. J Vect Ecol 33: 76-88.

Unlu I, Farajollahi A, Strickman D, Fonseca DM. 2013. Crouching tiger, hidden trouble: urban sources of Aedes albopictus (Diptera: Culicidae) refractory to source-reduction. PLoS One 8(10): e77999.

Waldock J, Parham PE, Lelieveld J, Christophides GK. 2013. Climate and human health: the impact of climate change on vector-borne diseases, Paphos, Cyprus (17-19 October 2012). Pathog Glob Health 107(8): 387-392.

Xue RD, Kline DL, Ali A, Barnard DR. 2006. Application of boric acid baits to plant foliage for adult mosquito control. J Am Mosq Control Assoc 22: 497-500.

Xue RD, Muller GC, Kline DL, Barnard DR. 2011. Effect of application rate and persistence of boric acid sugar baits applied to plants for control of Aedes albopictus. JAm Mosq Control Assoc 27: 56-60.

Zhu L, Marshall JM, Qualls WA, Schlein Y, McManus JW, Arheart KL, Hlaing WM, Traore SF, Doumbia S, Muller GC, Beier JC. 2015. Modelling optimum use of attractive toxic sugar bait stations for effective malaria vector control in Africa. Malaria J14: 492. 